\begin{tabular}{|c|c|c|c|}
\hline \multirow{3}{*}{$\begin{array}{r}\text { Case Reports in } \\
\text { Gastroenterology }\end{array}$} & \multirow{2}{*}{\multicolumn{2}{|c|}{ Case Rep Gastroenterol 2017;11:411-415 }} & \multirow[b]{3}{*}{$\begin{array}{l}\text { Karger } \\
\text { Open access }\end{array}$} \\
\hline & & & \\
\hline & $\begin{array}{l}\text { DOI: 10.1159/000477717 } \\
\text { Published online: July II, } 2017\end{array}$ & \begin{tabular}{|l} 
( 2017 The Author(s) \\
Published by S. Karger AG, Basel \\
www.karger.com/crg
\end{tabular} & \\
\hline & $\begin{array}{l}\text { This article is licensed under } \\
\text { International License (CC BY- } \wedge \\
\text { Usage and distribution for comn }\end{array}$ & $\begin{array}{l}\text { mons Attribution-NonCommercial } 4.0 \\
\text { rger.com/Services/OpenAccessLicense). } \\
\text { quires written permission. }\end{array}$ & \\
\hline
\end{tabular}

\title{
Fatal Gastrointestinal Hemorrhage in a Patient with Brunner's Gland Hyperplasia
}

\author{
Edward Meltser ${ }^{a} \quad$ Matthew Federici ${ }^{b}$ Robert Cooper $\mathrm{II}^{c}$ \\ Cristina Capanescu ${ }^{c}$ Kathryn C. Behling ${ }^{d, e}$ \\ ${ }^{a}$ Department of Pathology and Laboratory Medicine, Rutgers Robert Wood Johnson \\ Medical School, New Brunswick, NJ, USA; ${ }^{b}$ Cooper Medical School of Rowan University, \\ Camden, NJ, USA; 'Department of Gastroenterology, Cooper University Hospital, \\ Camden, NJ, USA; ${ }^{d}$ Department of Biomedical Sciences, Cooper Medical School of Rowan \\ University, Camden, NJ, USA; ${ }^{e}$ Department of Pathology, Cooper University Hospital, \\ Camden, NJ, USA
}

\section{Keywords}

Fatal gastrointestinal hemorrhage - Brunner's gland hyperplasia - Brunner's gland adenoma

\begin{abstract}
Brunner's gland hyperplasia is a rare cause of duodenal mass and gastrointestinal hemorrhage. Imaging and esophagoduodenoscopic evaluation of this condition are frequently consistent with a duodenal malignancy often resulting in surgical resection. However, the malignant potential of these lesions is still unknown, and most are benign. We report the case of a 74-year-old man who presented with fatal gastrointestinal bleeding and esophagoduodenoscopy findings consistent with a duodenal mass and mucosal ulceration. At autopsy, histologic examination of the mass revealed Brunner's gland hyperplasia with associated ulcer formation. In this report, we review the findings associated with this case as well the literature regarding presentation, clinical associations, and treatment of Brunner's gland hyperplasia.

(C) 2017 The Author(s)

Published by S. Karger AG, Basel
\end{abstract}

\section{Introduction}

Brunner's gland hyperplasia (BGH) is a rare cause of gastrointestinal bleeding [1]. BGH is part of a spectrum of Brunner's gland proliferation ranging from diffuse hyperplasia to 
polypoid lesions termed Brunner's gland adenomas/Brunner's gland hamartomas (BGA/ BGH) [2]. Rarely, malignant lesions have been reported to arise out of BGA/BGH [3]. Many patients with BGH or BGA/BGH are asymptomatic. However, some present with signs and symptoms of gastrointestinal bleeding or obstruction necessitating treatment [1, 4-8]. Imaging and endoscopic appearance in these cases often overlaps with that seen in malignancy, frequently leading to surgical removal [5, 8]. In this report, we present the case of a 74-yearold man with a fatal upper gastrointestinal hemorrhage secondary to mucosal ulceration in the second portion of the duodenum, which was involved by extensive BGH. We also review the current literature regarding clinical presentation, diagnostic workup, and treatment of this entity.

\section{Case Presentation}

A 74-year-old man with a past medical history significant for coronary artery disease complicated by dilated congestive cardiomyopathy and chronic atrial fibrillation, status post implantable cardioverter defibrillator placement and aortic bioprosthetic valve replacement presented to the hospital after an episode of hematochezia accompanied by nausea and pallor. On arrival, he was noted to have melenic stools, hypotension, and an acute drop in hemoglobin from a baseline of 8-9 to $5.6 \mathrm{~g} / \mathrm{dL}$. He was resuscitated with intravenous fluids and packed red blood cells and was intubated. A bedside esophagogastroduodenoscopy revealed irregular-appearing mucosa in the second part of the duodenum, concerning for malignancy (Fig. 1a, b), as well as several duodenal ulcers (Fig. 1c). A computed tomography scan of the abdomen and pelvis demonstrated arterial phase extravasation of blood into the duodenum (data not shown). Interventional radiology embolization was performed to control active bleeding of anterior pancreaticoduodenal arcade. The patient continued to have melenic stools, and his hemoglobin continued to fall, necessitating vasopressor support despite volume and blood product resuscitation. The patient was deemed a poor surgical candidate given his cardiac comorbidities, and the patient's family decided to initiate hospice care. The patient expired a short time thereafter, and an autopsy was performed.

At autopsy, gross examination revealed evidence of massive upper gastrointestinal bleeding including bloody gastric and intestinal contents. In the duodenum, near the ampulla, there was a circumferential area of mucosal irregularity measuring $4 \mathrm{~cm}$ in length, corresponding to the area seen on endoscopy (Fig. 1). A 1-cm mucosal ulceration was also identified within the area of mucosal irregularity. Histologic examination of the area of mucosal irregularity revealed extensive benign BGH with no evidence of dysplasia or malignancy (Fig. 2). A duodenal ulcer was also noted with extension of acute and chronic inflammation and fibrin through the muscularis propria and into the adjacent adipose tissue (Fig. 2a, b).

\section{Discussion}

$\mathrm{BGH}$ is a rare cause of upper gastrointestinal hemorrhage [1]. Brunner's glands are branched tubular mucus glands normally found in the mucosa and submucosa of the duodenum. These glands secrete mucus with an alkaline $\mathrm{pH}$, which serves to neutralize chyme from the stomach. This neutralization protects the duodenal mucosa and provides an optimal $\mathrm{pH}$ for pancreatic enzyme function [9]. 
BGH and BGA comprise about 3.9-10\% of all benign duodenal masses $[4,8,10]$ and less than $1 \%$ of all gastrointestinal tumors [8]. BGH is part of a spectrum of proliferation ranging from diffuse nodular hyperplasia, which was seen in our patient, to more circumscribed or pedunculated adenomatous/hamartomatous lesions [2]. Classification of these entities in the literature is variable with few established schemas. One frequently cited, Feyrter (1934) [2], describes three types of benign Brunner's gland lesions: type 1, diffuse nodular hyperplasia; type 2, circumscribed nodular hyperplasia; and type 3, glandular adenoma. Brunner's glands can be found throughout the duodenum; however, BGAs frequently occur more proximally and can be seen in association with acute/chronic duodenitis or erosive duodenitis [4]. BGH/BGAs are generally considered benign, and their malignant potential is unknown [6]. However, there are reports in the literature of occasional instances of malignancy developing in the background of BGH [3].

The cause of the BGH/BGA is currently unknown. Some have suggested an association with gastric hyperacidity. However, in one study, only $45 \%$ of patients had hyperacidity with $20 \%$ even having low acidity, suggesting that other stimuli may also play a role [5]. Additionally, Spellberg and Vucelic [11] showed no regression of BGH/BGA after treatment with inhibitors of acid secretion. Other possible inciting factors include $H$. pylori infection, local irritation, and parasympathetic hyperactivity [4]. BGH/BGA has also been seen in association with peptic ulcer disease. Notably, Fanzin et al. [12] found an association between BGA and hyperchloridia in patients with chronic gastric erosions and duodenal ulcers. Other reported associations include chronic renal failure, chronic pancreatitis [4], and groove pancreatitis [13]. In the current case, the patient did not have any of the aforementioned disorders, and the cause of the BGH seen at autopsy is unknown.

BGH/BGA is typically found in middle-aged patients. However, cases have been reported in patients ranging from under 1 year to 80 years [1]. Because these are generally benign lesions that are often asymptomatic, the true incidence is unknown. BGH/BGA also has no reported sex predilection $[1,4]$. Lesions typically range in size from 0.5 to $12 \mathrm{~cm}$ and are commonly seen near the junction of the first and second part of the duodenum [1]. In one study, $70 \%$ were found in the duodenal bulb, with $26 \%$ in the second part and $4 \%$ in the third part of the duodenum [1].

Many patients with BGH/BGA are asymptomatic. In one study, 11\% of BGH/BGA were found in asymptomatic patients [4]. Those that are symptomatic can present with occult or massive upper gastrointestinal bleeding or obstructive symptoms such as nausea, vomiting, abdominal pain, and early satiety $[1,4-8]$. Lesions in symptomatic patients also are typically larger in size [8]. Rare presentations include biliary obstruction, pancreatitis, duodenal intussusception, obstructive jaundice, and diarrhea [4]. When gastrointestinal bleeding is seen, it is typically occult, with melena four times more likely than hematemesis [4]. Notably, distal lesions are more likely to bleed than proximal lesions [4, 5]. Rarely, BGH/BGAs have been seen in association with fatal gastrointestinal hemorrhage [4], as was seen in our patient.

Diagnostic workup for BGH/BGA includes radiologic imaging and endoscopic examination. A barium swallow, which is most sensitive for identifying these lesions, can show filling defects in the area of pathology. However, this finding does not allow for distinction of this entity from malignant tumors found in this area $[4,5]$. Indeed, radiologic studies are often consistent with other submucosal lesions such as leiomyomas, lipomas, and lymphomas [8]. Endoscopic examination will demonstrate the lesion; however, biopsies may not be deep enough to sample the submucosal Brunner's glands that represent the true lesion [4]. The differential diagnosis of the endoscopic appearance generally includes adenomatous polyp, islet cell adenoma, ectopic pancreas, lipoma, angioma, leiomyoma, gastrointestinal stromal 
Meltser et al.: Fatal Gastrointestinal Hemorrhage in a Patient with Brunner's Gland Hyperplasia

tumor, and malignant tumors such as carcinoid tumors, adenocarcinomas, lymphomas, leiomyosarcomas, and metastases [7]. Even when BGH is seen on biopsy, lesions are often removed due to concerns for other more ominous pathology, as well as uncertainty as to the rate at which BGH/BGA will progress to malignancy or a more significant lesion [8].

BHG/BGA generally has a good prognosis. The nature of the lesion cannot always be ascertained by imaging or endoscopy, necessitating more invasive procedures to obtain tissue for histologic examination [8]. In symptomatic patients, lesions that are small and localized can be removed by endoscopy [1,4-8]. More extensive involvement may require surgical removal up to and including a pancreaticoduodenectomy [1, 4-8]. Asymptomatic patients are often treated conservatively with expectant management $[4,8]$.

\section{Statement of Ethics}

As this is a single case report, our institution does not require Institutional Review Board approval.

\section{Disclosure Statement}

The authors declare no conflict of interest.

\section{References}

1 Malik AA, Wani ML, Malik RA, Irshad I: Brunner's gland hyperplasia: an unusual cause of gastrointestinal bleeding. Turk J Gastroenterol 2011;22:419-421.

2 Feyrter F: Über Wucherungen der Brunnerschen Drüsen. Virchows Arch 1934;293:509-526.

-3 Kamei K, Yasuda T, Nakai T, Takeyama Y: A case of adenocarcinoma of the duodenum arising from Brunner's gland. Case Rep Gastroenterol 2013;7:433-437.

-4 Chattopadhyay P, Kundu AK, Bhattacharyya S, Bandyopadhyay A: Diffuse nodular hyperplasia of Brunner's gland presenting as upper gastrointestinal haemorrhage. Singapore Med J 2008;49:81-83.

-5 Janes SEJ, Zaitoun AM, Catton JA, Aithal GP, Beckingham IJ: Brunner's gland hyperplasia at the ampulla of Vater. J Postgrad Med 2006;52:38-40.

-6 Kibria R, Ali SA, Butt S, Akram S: Biliary obstruction and pancreatitis caused by diffuse nodular hyperplasia of Brunner's gland. J Gastrointest Canc 2009;40:128-130.

7 Kini JR, K H, Pai MR, Krishna N.R. SG, Tantry BV: Brunner's gland hamartoma and hyperplasia. Tropical Gastroenterology 2010;31:121-123.

8 Lu L, Li R, Zhang G, Zhao Z, Fu W, Li W: Bruner's gland adenoma of duodenum: report of two cases. Int J Clin Exp Pathol 2015;8:7565-7569.

9 Mescher AL: Junqueira’s Basic Histology: Text \& Atlas, 13e. New York, McGraw-Hill, 2013, Chapter 15. Digestive Tract.

http://accessmedicine.mhmedical.com/content.aspx?bookid=574\&sectionid=42524601. Accessed February 27, 2017.

10 Terada T: Pathologic observations of the duodenum of 615 consecutive duodenal specimens: 1 . benign lesions. Int J Clin Exp Pathol 2012;5:46-51.

11 Spellberg MA, Vucelic B: A case of Brunner's gland hyperplasia with diarrhoea responsive to cimetidine. Am J Gastroenterol 1980;73:519-522.

12 Fanzin G, Musola R, Ghidini O, Manfrini C, Fratton A: Nodular hyperplasia of Brunner's glands. Gastrointest Endosc 1985;31:374-378.

13 Balakrishnan V, Chatni S, Radhakrishnan L, Narayanan VA, Nair P: Groove pancreatitis: a case report and review of literature. J Pancreas (Online) 2007;8:592-597. 


\section{Case Reports in \\ Gastroenterology}

\begin{tabular}{l|l}
\hline Case Rep Gastroenterol 2017;11:411-415 \\
\hline DOI: 10.1159/000477717 & $\begin{array}{l}\text { ○ 2017 The Author(s). Published by S. Karger AG, Basel } \\
\text { www.karger.com/crg }\end{array}$ \\
\hline
\end{tabular}

Meltser et al.: Fatal Gastrointestinal Hemorrhage in a Patient with Brunner's Gland Hyperplasia
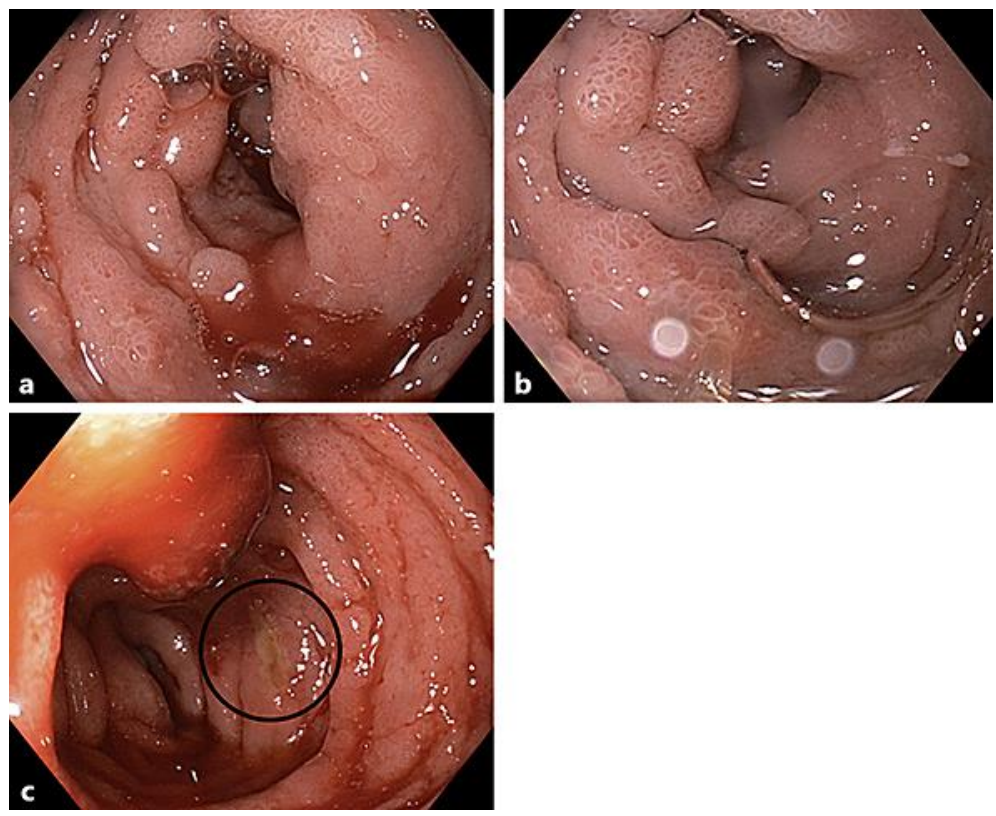

Fig. 1. Esophagoduodenoscopy. a, b Images from the second part of the duodenum show irregular mucosa concerning for malignancy. c Mucosal ulceration is also noted (black circle).

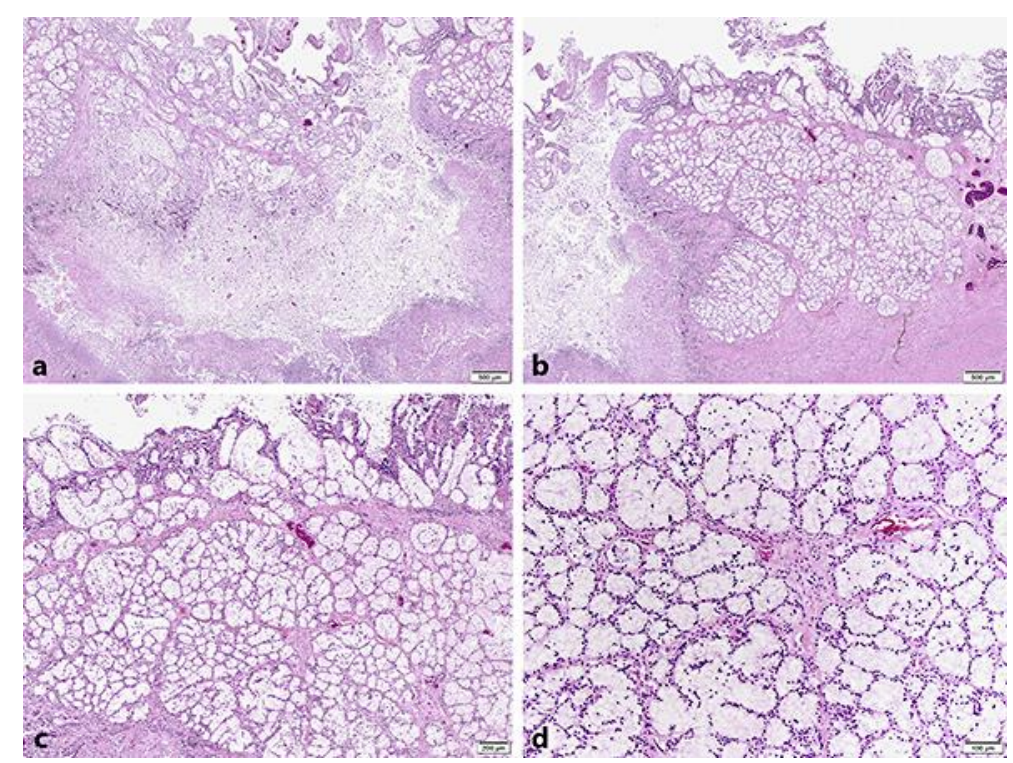

Fig. 2. Mucosal ulceration and Brunner's gland hyperplasia in the duodenum. $\mathbf{a}, \mathbf{b}$ Low-power images showing mucosal ulceration flanked by extensive Brunner's gland hyperplasia (20×). c Medium-power image showing proliferation of submucosal Brunner's glands $(40 \times)$. $d$ High-power image showing a benign proliferation of Brunner's glands without evidence of dysplasia or malignancy (100x). 